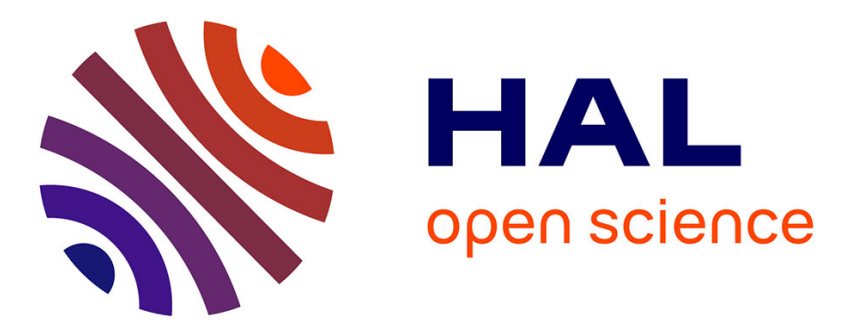

\title{
Intrinsic Folding of Small Peptide Chains: Spectroscopic Evidence for the Formation of Beta-turns in the Gas Phase
}

W. Chin,, Jean-Pierre Dognon, François Piuzzi, Benjamin Tardivel, Iliana Dimicoli, Michel Mons

\section{To cite this version:}

W. Chin, Jean-Pierre Dognon, François Piuzzi, Benjamin Tardivel, Iliana Dimicoli, et al.. Intrinsic Folding of Small Peptide Chains: Spectroscopic Evidence for the Formation of Beta-turns in the Gas Phase. Journal of the American Chemical Society, 2005, 127, pp.712. 10.1021/ja045251c . hal00081841

\section{HAL Id: hal-00081841 \\ https://hal.science/hal-00081841}

Submitted on 7 Sep 2006

HAL is a multi-disciplinary open access archive for the deposit and dissemination of scientific research documents, whether they are published or not. The documents may come from teaching and research institutions in France or abroad, or from public or private research centers.
L'archive ouverte pluridisciplinaire HAL, est destinée au dépôt et à la diffusion de documents scientifiques de niveau recherche, publiés ou non, émanant des établissements d'enseignement et de recherche français ou étrangers, des laboratoires publics ou privés. 


\section{Intrinsic Folding of Small Peptide Chains:}

\section{Spectroscopic Evidence for the Formation of $\beta$-turns in the Gas Phase}

Wutharath CHIN, Jean-Pierre DOGNON, François PIUZZI, Benjamin TARDIVEL, Iliana DIMICOLI and Michel MONS*

Laboratoire Francis Perrin (URA CEA-CNRS 2453), Service des Photons, Atomes et Molécules, Centre d'Etudes de Saclay, Bât. 522, 91191 Gif-sur-Yvette Cedex, France

e-mail : mmons@cea.fr

Title running head "Spectroscopy of $\beta$-turns in the gas phase" 


\begin{abstract}
Laser desorption of model peptides coupled to laser spectroscopic techniques enables the gas phase observation of genuine secondary structures of biology. Spectroscopic evidence for the formation of $\beta$ turns in gas phase peptide chains containing glycine and phenylalanine residues establishes the intrinsic stability of these forms and their ability to compete with other stable structures. The precise characterization of local minima on the potential energy surface from IR spectroscopy constitutes an acute assessment for the state-of-the-art quantum mechanical calculations on these systems. The observation of different types of $\beta$-turns depending upon the residue order within the sequence is found to be consistent with the residue propensities in $\beta$-turns of proteins, which suggests that prevalence of glycine in type II and II' turns stems essentially from an energetic origin, already at play under isolated conditions.
\end{abstract}

Keywords :

Protected peptide beta-turn UV spectroscopy IR spectroscopy

Gas phase Peptide folding Phenylalanine Glycine DFT calculations

TOC Synopsis Graphic

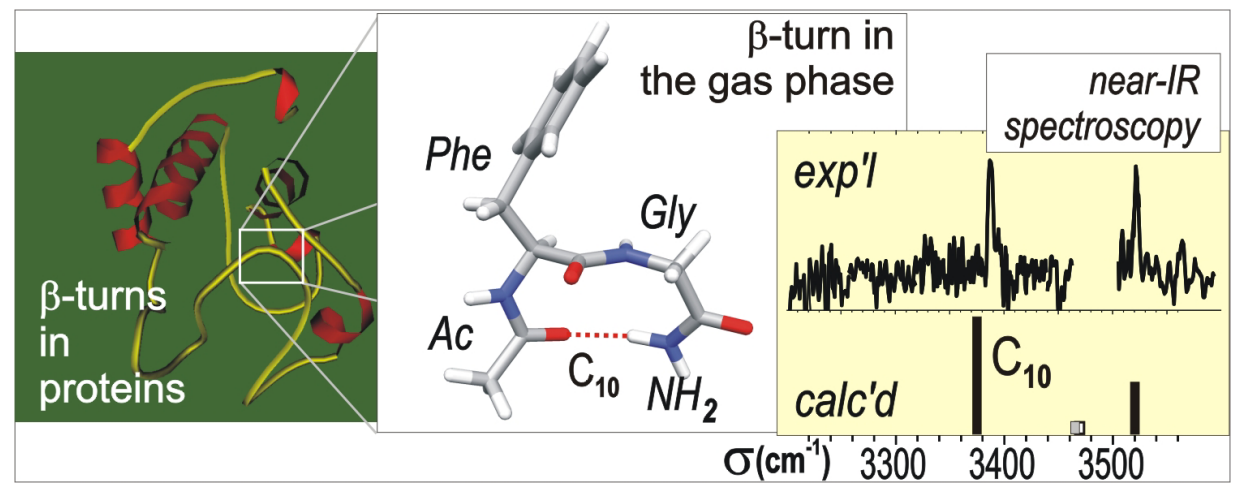




\section{Introduction}

$\beta$-turns, the smallest secondary structures of proteins, allow the peptide chain to fold back upon itself and play therefore a key role in the initiation of the folding process. X-ray structures of crystallized proteins have enabled biochemists to classify these chain reversals in terms of structure. ${ }^{1-6}$ Spanning over 4 amino-acid residues (labeled $i, \ldots i+3$ ), these folds are characterized by a H-bond bridging the $\mathrm{CO}(i)$ and $\mathrm{NH}(i+3)$ moieties, the so-called $\mathrm{C}_{10}$ interaction, named after the ten-membered ring formed (Scheme 1 and 2).

Scheme 1. $\beta$-turn within a

peptide sequence

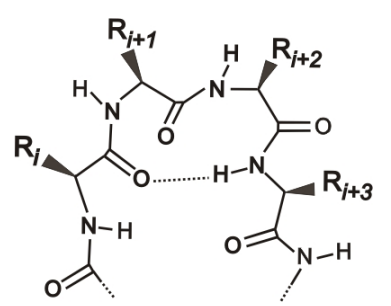

Four major types of turns (labeled I, II, I', and II') have been distinguished, based upon the Ramachandran $\varphi$ and $\psi$ dihedral angles controlling the relative orientations of the amide groups of the $i+1$ and $i+2$ central residues. ${ }^{3-6}$ In proteins, these secondary structures are in competition with other structures, either corresponding to local conformational preferences of the backbone about each residue, like $\beta$-sheets or $\gamma$-turns (based on $\mathrm{C}_{5}$ and $\mathrm{C}_{7}$ interactions respectively, see Scheme 2) or to helices based on intramolecular H-bonding schemes between more remote sites like $\mathrm{C}_{13}$ interactions.

Scheme 2. Intramolecular interactions in a protected peptide

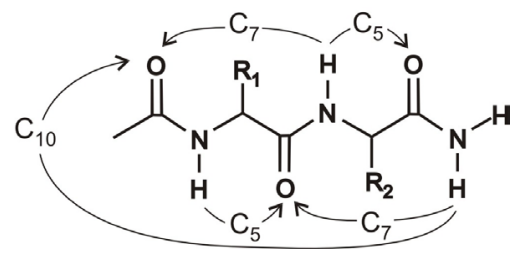


In order to investigate the role of local interactions in the formation of $\beta$-turns, biochemists and chemists have studied the intrinsic folding properties of model peptide chains, ${ }^{2,7-10}$ namely short synthesized peptide sequences containing a complete set of amide bonds, i.e., protected peptides by a $\mathrm{N}$-acetylation and a C-amidation. Such systems were investigated in solution two decades ago, using traditional techniques, like circular dichroïsm (CD), infrared (IR) absorption or Nuclear Magnetic Resonance (NMR). ${ }^{2,-10}$ The difficulty of these experiments, however, stems from the fact that, in solution, linear peptides present multiple forms, sometimes $\beta$-folded, but also $\gamma$-folded (corresponding to $\gamma$-turn) or extended. $\beta$-turns are usually minor conformations that are often difficult to detect among the condensed phase broad IR or CD spectra of the major conformers. ${ }^{2,7-10}$ NMR is here discarded because of its too long characteristic time scale compared to the interconversion occurring between these forms at room temperature. Apart from those containing the proline residue, the small linear peptides are often considered as not structured in solution and chemists interested in turn spectroscopy commonly use cyclic peptides to ensure the spontaneous formation of turns (generally two for each cyclic peptide, either the same type of turns, $\beta-\beta$, or mixed, $\beta-\gamma)$. Under such conditions, only a few experimental data from small peptide investigations could be useful for biochemistry modeling. In addition, these condensed phase data are not necessarily the most relevant for describing folding processes in a hydrophobic medium, like protein interior or lipidic membranes. In this respect, gas phase investigations of model peptides (Scheme 2) offer a unique approach to the structural and dynamical properties of a protein chain in an apolar environment, inasmuch as the precise data collected by the most recent techniques developed by experimental groups working on small biomolecules in the gas phase ${ }^{11-24}$ are directly comparable to the most sophisticated calculations currently available. $^{16,17,23-34}$

From a theoretical point of view, the potential energy surface (PES) of such small model systems is already complex. Its accurate exploration, description and characterization, needed for a complete understanding of dynamical processes, remains a difficult task. Recent progress in fast computers makes possible quantum mechanical studies on modified amino-acid and dipeptide model systems, 
launching new approaches ${ }^{25,30,32}$ to study the formation of secondary structures and their competition with other forms in vacuo. ${ }^{31,34}$ However, so far no relevant gas phase experimental counterpart data were available on peptide able to address the issue of $\beta$-folding, despite numerous works devoted to gas phase experimental studies of small peptides or model peptide chains, ${ }^{11-13,15-17,20-23}$ essentially focused on their local conformational preferences.

Aiming to bridge this gap between experiment and high-level theoretical calculations on secondary structures of peptides, we report here the first spectroscopic observation of $\beta$-turns in gas phase protected dipeptides and their characterization in terms of H-bonding.

The sequences studied (Scheme 2) exhibit two residues (labeled R1 and R2): glycine (Gly), chosen for its known ability to induce $\beta$-turns, ${ }^{5}$ and phenylalanine (Phe), which provides the UV chromophore needed in the experiment. The peptides are chemically protected on both ends, giving rise to a $\mathrm{N}$-acetyl group (Ac-) on the $\mathrm{N}$ terminal and an amino group $\left(-\mathrm{NH}_{2}\right)$ on the $\mathrm{C}$ terminal, so that they can be considered as segments of a protein chain. A simple protected amino acid, Ac-Phe- $\mathrm{NH}_{2}$, is also studied in order to document the intrinsic local conformational preferences of the peptide chain about an isolated Phe residue. The laser desorption technique coupled to a supersonic expansion ${ }^{14}$ allows to vaporize the peptide molecules and to cool them rotationally and vibrationally. This very efficient cooling combined to the spectral selectivity achieved with lasers enables us to perform conformationselective spectroscopy using double-resonance IR/UV techniques, ${ }^{35}$ in which the individual spectral contributions of each conformation, including minor ones, can be distinguished. ${ }^{16-18,20-24}$ Spectroscopic evidence for the formation of $\beta$-turn is first obtained from a fine analysis of the well-resolved IR features measured, and confirmed by comparison with the results of a detailed theoretical characterization of the potential energy surface for these species.

\section{Methods}

Experimental methods. The experimental set-up has been described in detail previously. ${ }^{14,18,21}$ Powder of the protected peptides (Epitop Co., Nîmes France) was mixed and compressed with 
spectroscopic grade powder graphite. The pellet obtained was fixed below the nozzle of a pulsed valve (General Valve Co. operating at $10 \mathrm{~Hz}$ ) and the sample molecules were desorbed from the pellet surface by the second harmonic output of a Nd:YAG laser (Continuum) guided to the sample through a multimode optical fiber. Molecules from the desorption plume are picked up and cooled down by the pulsed supersonic expansion of argon ( 4 bars backing pressure) and introduced through a $1 \mathrm{~mm}$ diameter skimmer in the interaction region of a time-of-flight mass-spectrometer. Molecules are photoionized in a resonant two-photon ionization process using the frequency-doubled output (typical pulse energy $1 \mathrm{~mJ}$ ) of an excimer-pumped dye laser (Lambda Physik FL 2002). The corresponding ion signals are sorted by the mass-spectrometer, collected and averaged in a PC-controlled LeCroy oscilloscope. Near UV spectra are obtained by scanning the dye laser in the origin region of the $\mathrm{S}_{1} \leftarrow \mathrm{S}_{0}$ transition of the Phe UV chromophore. The IR spectra of UV-selected conformations or the peptide studied have been obtained by the resonant ion-dip IR spectroscopy technique. ${ }^{35}$ The IR source is a Pérot-Fabry étalon-narrowed $\mathrm{LiNbO}_{3}$ optical parametric oscillator (OPO, Euroscan, $1 \mathrm{~cm}^{-1}$ linewidth, 3 mJ pulse energy) pumped by the fundamental beam of a Nd:YAG laser (Brilliant B, Quantel). The idler output, tunable in the $3 \mu \mathrm{m}$ region, is used to induce IR absorption transitions in the NH stretch (amide A) spectral region. The corresponding excitation leads to a transient depletion of the population of vibrationless molecules in the jet, which is detected by a depletion (ion-dip) in the ion signal due to the UV "probe" laser, shot typically 50 ns later. IR spectra are obtained by recording ion signals, both with and without the IR laser, using a PC-controlled shutter (Vincent Associates), and by normalizing the difference with the ion signal in absence of IR light, therefore providing zero-baseline depletion spectra. Due to absorption by impurities in the OPO crystal, a large drop in IR intensity is observed in the $3460-3500 \mathrm{~cm}^{-1}$ region, due to the non-linearity of the light generation, forbidding any spectral recording. This is indicated by the absence of experimental trace in the ion-dip IR spectra.

Theoretical methods: In order to provide a complete and refined picture of the potential energy landscape of the peptide studied, a set of low energy conformations has first been generated using several strategies: by exploring the PES using the Cornell et al. force field, ${ }^{36}$ by combining local 
conformational preferences known for each residue and by simply considering the canonical types of $\beta$ turns of biology ${ }^{5}$. All these structures have then been refined using the Density Functional Theory (DFT) method (B3LYP/6-31+G(d) level of theory) and their harmonic vibrational frequencies have been calculated using the Gaussian 98 program. ${ }^{37}$. A post-Hartree-Fock method (single point MP2/6$31+\mathrm{G}(\mathrm{d})$ on the B3LYP-optimized geometry) has finally been used to account for electronic correlation.

\section{Experimental Results}

The UV spectra of the peptides studied (Fig. 1) measured in the absorption region of Phe (first $\pi \pi^{*}$ transition) present resolved narrow features, illustrating the efficiency of the cooling process in the expansion, ending up with a very small number of finally populated structures. The vibrational progressions observed correspond to significant vibrational excitations, simultaneous to the electronic excitation. This Franck-Condon vibrational activity, controlled by the geometry changes between ground and excited states, reveals information upon the Phe chromophore environment. In this respect

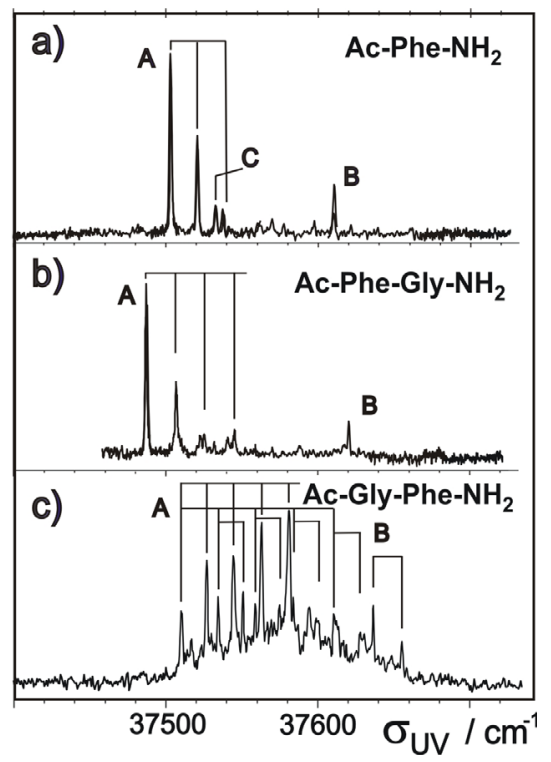

Figure 1. UV spectra of Ac-Phe- $\mathrm{NH}_{2}$ (a), Ac-Phe-Gly- $\mathrm{NH}_{2}$ (b) and Ac-Gly-Phe- $\mathrm{NH}_{2}$ (c) in the origin region of the first electronic transition $\left(\pi \pi^{*}\right)$, as obtained in supersonic expansion by mass-selected resonant two-photon ionization. Double-resonance IR/UV experiments demonstrate that only a few conformations are responsible for the spectra observed. The origin transition of each conformer is identified by its label (A, B or C). 
the spectra of the most populated conformation of Ac-Phe- $\mathrm{NH}_{2}$ and Ac-Phe-Gly- $\mathrm{NH}_{2}$ (labeled A) are similar, suggesting comparable Phe environments in these two species. In contrast, the qualitatively different spectrum of Ac-Gly-Phe- $\mathrm{NH}_{2}$ pleads for a different geometrical arrangement. Besides the most populated species of these dipeptides, one minor conformer (labeled B) was also evidenced from its weak UV signature and identified from its IR spectroscopy.

The IR spectra of the protected peptides studied (Fig. 2) exhibit well-resolved absorption bands, all corresponding to the stretching of the $\mathrm{NH}$ bonds in the molecule. Compared to the broad IR spectra in solution ${ }^{2,7-9}$, the present results emphasize the efficiency of the laser-selective gas-phase data to provide resolved features and to distinguish each IR chromophore of each conformation detected in the jet.

A qualitative assignment can be derived from the sensitivity of the $\mathrm{NH}$ stretch motion to the environment of the $\mathrm{NH}$ bond, in particular its involvement in a H-bond. Whereas unperturbed $\mathrm{NH}$ stretches absorb in the $3450-3500 \mathrm{~cm}^{-1}$ range, the occurrence of intense, broadened and significantly red-shifted bands (frequency $<3420 \mathrm{~cm}^{-1}$ ), is the unambiguous signature of an intramolecular $\mathrm{H}$ bonding. The presence of IR bands in the intermediate $\left(3420-3450 \mathrm{~cm}^{-1}\right)$ region indicates weaker interactions upon the $\mathrm{NH}$ group considered, like $\mathrm{C}_{5}$ or $\mathrm{NH}$-aromatic interactions. Crucial structural assignment information is also derived from the IR signature of the C-terminal amino group and its dependence upon H-bonding. ${ }^{21}$ When free from H-bonding, the vibrationally coupled $\mathrm{NH}$ oscillators give rise to a doublet split by $117 \mathrm{~cm}^{-1} \cdot{ }^{21,38,39}$. Any increase of this splitting, together with the slight redshift of the blue antisymmetric component in the $3500-3530 \mathrm{~cm}^{-1}$ range, provides information onto the involvement of one of the NH oscillators within the intramolecular H-bonding network and enables us to estimate the H-bond strength. ${ }^{21,39}$

This is exemplified by the IR spectra of Ac-Phe- $\mathrm{NH}_{2}$ (Fig 2a), which reflects the local conformational preferences for a Phe residue ${ }^{21,22,40}$ and will be used as a guide for the assignment of dipeptide spectra. The most populated form A corresponds to an extended $\beta$ sheet-like peptide backbone (labeled $\beta_{\mathrm{L}}$ according to Ramachandran terminology), stabilized by two rather weak 
interactions, one $\mathrm{C}_{5}$ bond, taking place between the close lying $\mathrm{NH}(i)$ and $\mathrm{CO}(i)$ moieties of the Phe residue and a $\mathrm{NH}-\pi$ ring interaction made possible in the anti orientation of the Phe side-chain. Both

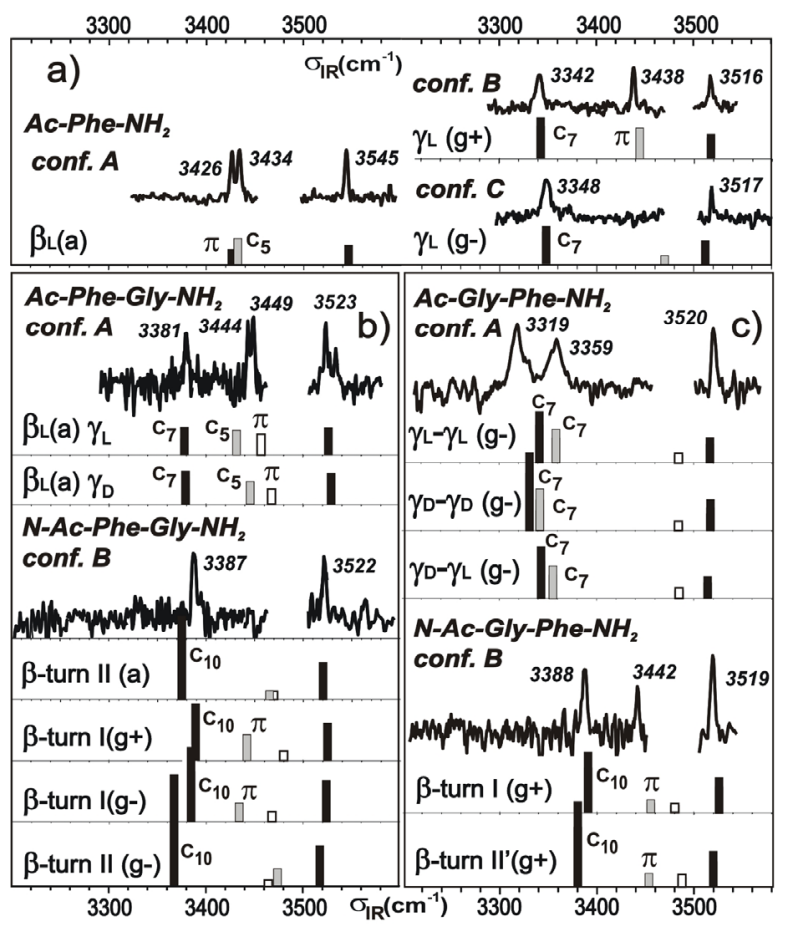

Figure 2. Resonant ion-dip IR spectroscopy (amide NH stretch region) of the conformations of AcPhe- $\mathrm{NH}_{2}$ (a), Ac-Phe-Gly- $\mathrm{NH}_{2}$ (b) and Ac-Gly-Phe- $\mathrm{NH}_{2}$ (c) selected from the origin bands identified in the UV spectra of Fig. 1. For comparison are also given DFT calculated stick spectra (Tables S3 and S4) of the most stable conformations (Fig. 3 and 4) matching the experimental number of $\mathrm{H}$-bonds $\left(\mathrm{C}_{7}\right.$ or $\left.C_{10}\right)$. Conformations are labeled according to the successive backbone conformations $\left(\gamma_{L}, \gamma_{D}, \beta\right)$ on each residue, or to the corresponding type for $\beta$-turns, and using the classical terminology to describe the Phe side-chain orientation (a, g+ or g-, standing for anti, gauche+ or gauche- respectively). Harmonic frequencies are scaled by a factor of 0.960 , adjusted on Ac- $\mathrm{Phe}_{\mathrm{NH}} \mathrm{Nata}^{21}$ to account for anharmonicity. The weak coupling between the several NH stretch oscillators enables a local assignment of the vibrational motions indicated by a color code (black: C-terminal $\mathrm{NH}_{2}$; grey: $\mathrm{NH}(\mathrm{Phe})$ and white: $\mathrm{NH}(\mathrm{Gly}))$. The assignment of the red shifted bands in terms of type of interaction is given on the stick spectra. 
interactions are observable in the spectra as causing only a slight red shift of the NH stretch bands. On the other hand, minor B and C conformers exhibit significantly red shifted IR bands, which are assigned to intramolecular $\mathrm{C}_{7} \mathrm{H}$-bonds. These two $\gamma$-folded species ( $\gamma_{\mathrm{L}}$ conformations) differ by the orientation of the Phe side-chain. The local backbone conformational preferences observed for a Phe residue, $\beta$ sheet-like $\beta_{\mathrm{L}}$ and $\gamma$-folded, are satisfactorily found as the lowest energy conformers (Fig. 2a) in MP2 calculations, which illustrates the ability of this method to account for dispersive and weakly polar interactions, like NH- $\pi$ contacts. $^{21,41}$ Interestingly, gas phase microwave experiments and ab initio calculations on the protected amino-acids glycine ${ }^{27}$ and alanine ${ }^{27,42}$ show that the conformational preference of both Gly and Ala residues is the $\gamma_{\mathrm{L}}$-folded $\mathrm{C}_{7}$ form alone, which demonstrates, in the case of Phe, the active role of the side-chain/backbone interactions in stabilizing $\beta_{\mathrm{L}}$ conformations. ${ }^{41}$

Taking advantage of the knowledge of the spectral signatures of the $\mathrm{C}_{7} \mathrm{H}$ bonds as well as of the weaker $\mathrm{C}_{5}$ and $\pi$ interactions, a qualitative assignment can already be proposed for the protected dipeptides.

- For the main conformers A, red-shifts in the IR bands of Ac-Phe-Gly- $\mathrm{NH}_{2}$ and Ac-Gly-Phe- $\mathrm{NH}_{2}$ (Fig. $2 \mathrm{~b}, 2 \mathrm{c}$ ) indicate the presence of one and two H-bonds respectively, as well as, in both cases the involvement of the terminal $\mathrm{NH}_{2}$ group in these $\mathrm{H}$-bonds. Because $\mathrm{C}_{7}$ and $\mathrm{C}_{10} \mathrm{H}$ bonds cannot occur simultaneously on the same $\mathrm{CO}$ acceptor for evident geometrical reasons, ${ }^{3}$ only $\mathrm{C}_{7}-\mathrm{C}_{7}$ structures can account for the doubly bond Ac-Gly-Phe- $\mathrm{NH}_{2}$ main form. In the case of Ac-Phe-Gly- $\mathrm{NH}_{2}$, however, either a $\mathrm{C}_{7}$ or a $\mathrm{C}_{10} \mathrm{H}$-bond involving the $\mathrm{NH}_{2}$ group can be responsible a priori for the spectrum observed. However, the striking similarities of the UV spectra of Ac-Phe- $\mathrm{NH}_{2}$ (A) and Ac-Phe-Gly$\mathrm{NH}_{2}$ (A) (Fig. 1a and 1b) suggests a very similar backbone environment for the Phe ring in both species, therefore a $\beta_{\mathrm{L}}(\mathrm{a})$ conformation. In such a case, because of the extended nature of the $\beta_{\mathrm{L}}$ conformation, a $\mathrm{C}_{10} \mathrm{H}$ bond can be ruled out suggesting that a $\mathrm{C}_{7}$ bond is located on the Gly residue. This assignment is comforted by the IR spectrum of Ac-Phe-Gly- $\mathrm{NH}_{2}$ (A) (Fig. 2b) : the similarities in the red-shift region with those of forms $\mathrm{A}$ and $\mathrm{B}$ of $\mathrm{Ac}-\mathrm{Phe}-\mathrm{NH}_{2}$ are consistent with a weak $\mathrm{C}_{7}$ bond as well as $\mathrm{C}_{5}$ and $\mathrm{NH}-\pi$ interactions taking place simultaneously in the structure. 
- The minor conformers B are both characterized by a single H-bond, originating from the terminal $\mathrm{NH}_{2}$ group as testified by the red-shift of the antisymmetric $\mathrm{NH}_{2}$ stretch band. Moreover, the significantly smaller splitting of the $\mathrm{NH}_{2}$ doublet, compared to that in $\gamma_{\mathrm{L}}$ conformers (B and C) of AcPhe- $\mathrm{NH}_{2}$ (Fig. 2), suggests a rather weak type of H-bonding for this group, in particular differing from that observed in the main conformations. Owing to the qualitatively different character of the $\mathrm{H}$ band established by the $\mathrm{NH}_{2}$ group compared to the case of main conformers, a $\mathrm{C}_{10}$-type assignment, i.e. $\beta$ turn like structures, can be proposed for these forms.

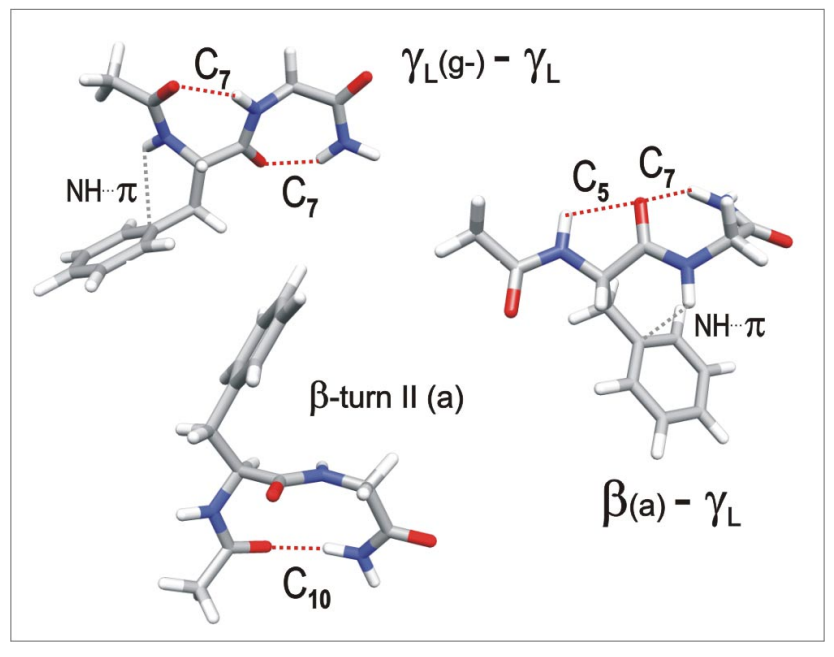

Figure 3. Selected DFT-optimized (B3LYP/6-31+G(d)) conformations of the model peptide Ac-PheGly-NH2, showing the $\mathrm{C}_{7}$ and $\mathrm{C}_{10} \mathrm{H}$-bonds and the weak $\left(\mathrm{NH}-\pi\right.$ and $\left.\mathrm{C}_{5}\right)$ intramolecular interactions.

\section{Theoretical results}

The present assignment has been assessed by comparison to theoretical investigations. The energetic landscape of a protected dipeptide is complex, owing to the large number of conformations a priori expected $\left(3^{5}=243\right)$, on the basis of three minima per $\mathrm{C}-\mathrm{C}$ or $\mathrm{C}-\mathrm{N}$ bond and three possible Phe sidechain orientations. The PES explorations, however, allowed us to distinguish two groups of conformations, or basins (Fig. 3 and 4; Supplementary information: Tables S1 and S2), able to play a role under jet conditions (providing that all the peptide units are in the trans form, as usually observed in peptides and proteins not containing proline residues ${ }^{43}$ ). The first basin is composed of 
conformations in which the local preferences about each residue $\left(\beta_{\mathrm{L}}\right.$ or $\left.\gamma_{\mathrm{L}}\right)$ are retained at least partially. They exhibit two, one or no H-bond(s), depending upon the number of $\gamma$-folds that are present and lead to "open" backbone structures, in which end amide groups do not interact. The second class ( $\beta$-folds) contains the four types of $\beta$-turns with their $\mathrm{C}_{10} \mathrm{H}$-bond. It should be noticed that, unlike the Ac-Phe- $\mathrm{NH}_{2}$ case, the two basins of the dipeptides are probably separated by high-lying barriers, that may not be easily crossed over during the desorption/expansion process. Hence the final basin populations do probably reflect a free energy ordering pertaining to the early times of the expansion rather than relative stabilities under cold conditions.

\section{Discussion}

The UV and IR data of Ac-Phe-Gly-NH2 (Fig. 1b, 2b) and Ac-Gly-Phe-NH $\mathrm{NH}_{2}$ (Fig. 1c, 2c) can be accounted for by one of the lowest energy structures found for these species.

Comparison with calculated spectra of the lowest structures of the open basin (Fig. 3 and 4) shows that the successive local preferences of the backbone $\left(\beta_{\mathrm{L}}\right.$ or $\gamma_{\mathrm{L}}$ for Phe, $\gamma_{\mathrm{L} / \mathrm{D}}$ for Gly) are retained in the dipeptide, leading to the competing $\gamma-\gamma\left(\mathrm{C}_{7}-\mathrm{C}_{7}\right)$ and $\beta-\gamma\left(\mathrm{C}_{5}-\mathrm{C}_{7}\right)$ locally folded forms. Depending upon the NH- $\pi$ interactions occurring, either one or the other form is finally populated in the jet: $\gamma-\gamma$ for AcGly-Phe- $\mathrm{NH}_{2}$ and $\beta-\gamma$ for Ac-Phe-Gly-NH . This explains the resemblance of the UV spectrum of the latter species to that of the $\beta_{\mathrm{L}}\left(\mathrm{C}_{5}\right)$ conformer of $\mathrm{Ac}-\mathrm{Phe}-\mathrm{NH}_{2}$, due to their similar Phe environment. The repeated $\gamma$-turn pattern corresponds actually to a short segment of the so-called 27 ribbon, conjectured by biochemists long time ago and observed only rarely in proteins as transition structures at the ends of longitudinally compressed $\beta$-strands. ${ }^{44}$ One will notice that the most stable structure of the "open" type experimentally observed for both peptides does match the minimum of the corresponding basin at the MP2 level (Fig. 4), in contrast to DFT predictions (Tables S1 and S2), which seem to overestimate the $\beta_{\mathrm{L}}$ stability and underestimate $\mathrm{NH}-\pi$ interactions. This finding illustrates the interest of 
the gas phase experiments as benchmark data in assessing the quality of high accuracy energetic calculations on peptide chains.

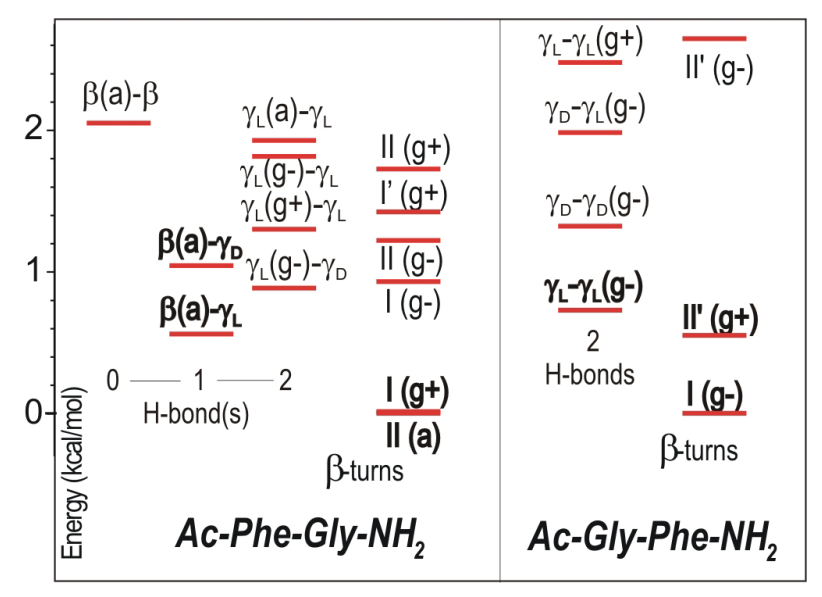

Figure 4. Energetic landscape (MP2/6-31+G(d)//B3LYP/6-31+G(d) level corrected for zero-point vibrational energy) of the protected dipeptides Ac-Phe-Gly- $\mathrm{NH}_{2}$ (left) and Ac-Gly-Phe- $\mathrm{NH}_{2}$ (right), showing the relative energies of the two main basins ("open" forms vs. $\beta$-turns). Conformations are identified by their local conformation about each residue according to Ramachandran classification; Phe side-chain orientations are given in brackets. In the first basin, competition between local backbone preferences $(\gamma, \beta)$ gives rise to both energetically and topologically close structures $(\gamma-\gamma$ vs. $\beta-\gamma$ or $\gamma-\beta$ ). For both peptides, the $\beta$-turn basin is very close in energy. One will notice however that the most stable type of turn changes with the sequence. The calculated forms in agreement with experimental data are indicated in bold.

For the minor conformers B, comparison of IR data with calculations (Fig. 2b and 2c) leads to a fair agreement with the $\mathrm{C}_{10} \mathrm{H}$-bond of the most stable $\beta$-turns found at the MP2 level. In Ac-Gly-Phe- $\mathrm{NH}_{2}$, the two lowest calculated $\beta$-turns (of type I and II') do possess the same $\mathrm{NH}-\pi$ signature so that no further experimental assignment is possible. However, the two most stable types of $\beta$-turns for Ac-PheGly- $\mathrm{NH}_{2}$ (type I and II), found to be nearly isoenergetic at the MP2 level, exhibit different NH- $\pi$ 
interactions, which enables us to assign the actual most stable $\beta$-turn to a type II, and indicates the limitations of the present level of theory for energetic relevance.

The present work on gas-phase peptide models reveals several properties of the peptide chain, from well-resolved details of the conformation-selective IR spectroscopy. Both $\beta$ - and $\gamma$-foldings appear as intrinsic properties of the peptide chain, stemming upon the flexible nature of the backbone. This turns out to be a general feature, still observed when the Gly is replaced by a more bulky side-chain (Ala or Val). ${ }^{45}$ The particular role of the side-chain/backbone interactions (namely NH- $\pi$ interactions) is also emphasized since they are shown to alter the backbone preferences, by controlling the competition between several nearly isoenergetic minima, like the topologically close $\gamma-\gamma$ and $\beta_{L}-\gamma$ structures, or the several orientations of the Phe side-chain with respect to the backbone. These findings are not accessible in liquid phase data, owing to the poor resolution achieved in this medium. In addition, the present data illustrate the resemblance between the spectral IR features of $\beta$-turns and $\beta_{\mathrm{L}-} \gamma$ structures, which makes problematic their distinction in the liquid phase. In this respect, one should notice that the use of a $-\mathrm{NH}_{2}$ protection on the C-terminal, instead of the more canonical $-\mathrm{N}(\mathrm{H})-\mathrm{CH}_{3}$ ending, makes unambiguous the assignment of the $\beta$-turn $\mathrm{C}_{10}$ band thanks to the additional red-shift due to the $\mathrm{NH}_{2}$ vibrational coupling. ${ }^{21}$ In the absence of such an effect, the small red-shift of the weak $\mathrm{C}_{10}$ band might be confused, in solution and gas phase as well, with weaker interactions, like a $\mathrm{C}_{5}$ bond of a $\beta_{\mathrm{L}}$ conformation for instance.

The $\beta$-turns of biology are observed as minor conformations but are common in the series of dipeptides experimentally investigated so far ${ }^{45}$. Their most striking feature is the $\mathrm{C}_{10} \mathrm{H}$-bond, whose strength is rather weak compared to the $\mathrm{C}_{7}$ bond, but independent upon the sequence in marked contrast with the $\gamma$-folding (Fig. 2). The energetic competition between these forms is probably due to a different balance between $\mathrm{H}$-bonding and backbone strains: the lower strength of the $\mathrm{C}_{10} \mathrm{H}$-bond compared to the $C_{7}$ bond is compensated for by weaker backbone strains in $\beta$-turns compared to $\gamma$ folding. Calculations indeed show that, in $\gamma-\gamma$ and $\beta-\gamma$ structures, the $\mathrm{C}-\mathrm{N}$ bond of the central amide is 
significantly shortened by typically $0.01 \AA$, compared to the terminal amide groups. No such differences are found in $\beta$-turns.

Comparison of gas phase IR spectra with quantum chemistry calculations indicates that the intrinsically most stable type of $\beta$-turn is sequence-dependent. More generally, when averaged over the three possible orientations of the Phe side-chain, calculations lead to the following type preferences: type II for Ac-Phe-Gly-NH $\mathrm{NH}_{2}$ and type II' followed by I for Ac- Gly-Phe- $\mathrm{NH}_{2}$ (Tables S1 and S2). This result can be compared to the so-called "residue potentials" derived by biochemists from data mining on X-ray diffraction spectra of crystallized proteins ${ }^{1,5,46}$. Indeed, types II and II', which represent respectively $20 \%$ and $4 \%$ of all the classified turns, have been recognized as nearly exclusively specific of the glycine residue in one of the central positions of the turn, namely $i+2$ and $i+1$ positions respectively. Whereas biochemistry potentials illustrate the occurrence frequency of residues in turns in a biochemical environment, the conformational preferences deduced from the present gas phase studies reflect the intrinsic $\beta$-turn inducing power of the Gly residue, free of any environment effect (neighboring residues, remote parts of the protein, etc..). The correlation observed between gas phase and protein data suggests therefore that, for the small Gly residue, i) the preference for types II and II' is an intrinsic property, already at play in the gas phase, in the absence of environment, and ii) this preference is not affected in biological environments, probably because of the absence of side-chain: the eventual environment effects, usually acting through interactions of remote parts of the protein upon the side-chain, remain indeed negligible with Gly.

The present UV and IR optical study of $\beta$-turns illustrates the relevance of gas phase studies to probe minima on the PES of a small biomolecule in details. Combined to the most recently developed experimental approaches ${ }^{17,23}$ focused onto the ground state dynamics, such studies also open up the way to a direct probe of the folding process of a small peptide chain. Finally, the spectral resolution achieved in the gas phase with lasers enables us to envisage applying the same methodologies on biomolecules of larger size, able to form more complex secondary structures, like $3_{10}$ or $\alpha$ helices. 
Supporting Information Available : The energetic (B3LYP/6-31+G(d) and MP2/6$31+\mathrm{G}(\mathrm{d}) / / \mathrm{B} 3 \mathrm{LYP} / 6-31+\mathrm{G}(\mathrm{d}))$ and geometrical parameters of the minimum energy structures found for Ac-Phe-Gly- $\mathrm{NH}_{2}$ and Ac-Gly-Phe- $\mathrm{NH}_{2}$ are gathered in Tables S1 and S2. The corresponding calculated harmonic frequencies and IR intensities are given for the most stable forms and compared to experimental frequencies in Tables S3 and S4.

\section{References}

(1) Chou, P. Y.; Fasman, G. D. J. Mol. Biol. 1977, 115, 135.

(2) Smith, J. A.; Pease, L. G. CRC Crit. Rev. Biochem. 1980, 8, 314 and ref. therein.

(3) Toniolo, C. CRC Crit. Rev. Biochem. 1980, 9, 1.

(4) Richardson, J. S. Adv. Prot. Chem. 1981, 34, 167.

(5) Hutchinson, E. G.; Thornton, J. M. Protein Science 1994, 3, 2209 and ref. therein.

(6) Chou, K. Analytical Biochem. 2000, 286, 1 and ref. therein.

(7) Rose, G. D.; Gierasch, L. M.; Smith, J. A. Adv. Prot. Chem. 1985, 37, 1 and ref. therein.

(8) Boussard, G.; Marraud, M. J. Am. Chem. Soc. 1985, 107, 1825 and ref. therein.

(9) Liang, G.-B.; Rito, C. J.; Gellman, S. H. J. Am. Chem. Soc. 1992, 114, 4440 and ref. therein.

(10) Vass, E.; Hollosi, M.; Besson, F.; Buchet, R. Chem. Rev. 2003, 103, 1917 and ref. therein.

(11) Zwier, T. S. J. Phys. Chem. A 2001, 105, 8827 and ref. therein.

(12) Robertson, E. G.; Simons, J. P. Phys. Chem. Chem. Phys. 2001, 3, 1 and ref. therein.

(13) Cable, J. R.; Tubergen, M. J.; Levy, D. H. J. Am. Chem. Soc. 1989, 111, 9032.

(14) Piuzzi, F.; Dimicoli, I.; Mons, M.; Tardivel, B.; Zhao, Q. Chem. Phys. Lett. 2000, 320, 282.

(15) Cohen, R.; Brauer, B.; Nir, E.; Grace, L.; de Vries, M. S. J. Phys. Chem. A 2000, 104, 6351.

(16) Dian, B. C.; Longarte, A.; Mercier, S.; Evans, D. A.; Wales, D. J.; Zwier, T. S. J. Chem. Phys. 2002, 117, 10688.

(17) Dian, B. C.; Longarte, A.; Zwier, T. S. Science 2002, 296, 2369. 
(18) Mons, M.; Dimicoli, I.; Piuzzi, F.; Tardivel, B.; Elhanine, M. J. Phys. Chem. A 2002, $106,5088$.

(19) Dong, F.; Miller, R. E. Science 2002, 298, 1227.

(20) Unterberg, C.; Gerlach, A.; Schrader, T.; Gerhards, M. J. Chem. Phys. 2003, 118, 8296 and ref. therein.

(21) Chin, W.; Mons, M.; Dognon, J.-P.; Piuzzi, F.; Tardivel, B.; Dimicoli, I. Phys. Chem. Chem. Phys. 2004, 6, 2700.

(22) Gerhards, M.; Unterberg, C.; Gerlach, A.; Jansen, A. Phys. Chem. Chem. Phys. 2004, 6, 2682.

(23) Dian, B. C.; Clarkson, J. R.; Zwier, T. S. Science 2004, 303, 1169.

(24) Jockusch, R. A.; Kroemer, R. T.; Talbot, F. O.; Snoek, L. C.; Çarçabal, P.; Simons, J. P.; Havenith, M.; Bakker, J. M.; Compagnon, I.; Meijer, G.; von Helden, G. J. Am. Chem. Soc. 2004, 126, 5709 and ref. therein.

(25) Perczel, A.; Csizmadia, I. G. Int. Rev. Phys. Chem. 1995, 14, 127 and ref. therein.

(26) Perczel, A.; Farkas, O.; Csaszar, A. G.; Csizmadia, I. G. Can. J. Chem.-Rev. Can. Chim. 1997, 75, 1120 .

(27) Endredi, G.; Perczel, A.; Farkas, O.; McAllister, M. A.; Csonka, G. I.; Ladik, J.; Csizmadia, I. G. J. Mol. Struct. (Theochem) 1997, 391, 15.

(28) Csaszar, A. G.; Perczel, A. Prog. Biophys. Mol. Biol. 1999, 71, 243.

(29) Hudaky, P.; Jakli, I.; Csaszar, A. G.; Perczel, A. J. Comput. Chem. 2001, 22, 732.

(30) Perczel, A.; Jakli, I.; McAllister, M. A.; Csizmadia, I. G. Chem.-Eur. J. 2003, 9, 2551 and ref. therein.

(31) Perczel, A.; Jakli, I.; Csizmadia, I. G. Chem.-Eur. J. 2003, 9, 5332 and ref. therein.

(32) Möhle, K.; Gussmann, M.; Hofmann, H. J. J. Comput. Chem. 1997, 18, 1415 and ref. therein.

(33) Möhle, K.; Gussmann, M.; Rost, A.; Cimiraglia, R.; Hofmann, H. J. J. Phys. Chem. A 1997, 101, 8571 .

(34) Möhle, K.; Hofmann, H. J. J. Mol. Model. 1998, 4, 53 and ref. therein.

(35) Pribble, R. N.; Zwier, T. S. Science 1994, 265, 75 and ref. therein.

(36) Cornell, W. D.; Cieplak, P.; Bayly, C. I.; IGould, I. R.; Merz, K. M.; Ferguson, D. M.; Spellmeyer, D. C.; Fox, T.; Caldwell, J. W.; Kollman, P. A. J. Am. Chem. Soc. 1995, 117, 5179.

(37) Frisch, M. J.; Trucks, G. W.; Schlegel, H. B.; Scuseria, G. E.; Robb, M. A.; Cheeseman, J. R.; Zakrzewski, V. G.; Montgomery, J. A.; Stratmann, R. E.; Burant, J. C.; Dapprich, S.; Millam, J. M.; Daniels, A. D.; Kudin, K. N.; Strain, M. C.; Farkas, O.; Tomasi, J.; Barone, V.; Cossi, M.; Cammi, R.; Mennucci, B.; Pomelli, C.; Adamo, C.; Clifford, S.; Ochterski, J.; Petersson, G. A.; Ayala, P. Y.; 
Cui, Q.; Morokuma, K.; Malick, D. K.; Rabuck, A. D.; Raghavachari, K.; Foresman, J. B.; Cioslowski, J.; Ortiz, J. V.; Stefanov, B. B.; Liu, G.; Liashenko, A.; Piskorz, P.; Komaromi, I.; Gomperts, R.; Martin, R. L.; Fox, D. J.; Keith, T.; Al-Laham, M. A.; Peng, C. Y.; Nanayakkara, A.; Gonzalez, C.; Challacombe, M.; Gill, P. M. W.; Johnson, B. G.; Chen, W.; Wong, M. W.; Andres, J. L.; HeadGordon, M.; Replogle, E. S.; Pople, J. A.; Revision A7 ed.; Gaussian, Inc.: Pittsburg, PA, USA, 1998.

(38) Robertson, E. G.; Hockridge, M. R.; Jelfs, P. D.; Simons, J. P. Phys. Chem. Chem. Phys. 2001, 3, 786 .

(39) Nakanaga, T.; Ito, F. J. Phys. Chem. A 1999, 103, 5440.

(40) Chass, G. A.; Lovas, S.; Murphy, R. F.; Csizmadia, I. G. Eur. Phys. J. D 2002, 20, 481.

(41) Chin, W.; Mons, M.; Dognon, J.-P.; Mirasol, R.; Chass, G. A.; Dimicoli, I.; Piuzzi, F.; Butz, P.; Tardivel, B.; Compagnon, I.; von Helden, G.; Meijer, G., submitted.

(42) Lavrich, R. J.; Plusquellic, D. F.; Suenram, R. D.; Fraser, G. T.; Walker, A. R. H.;

Tubergen, M. J. J. Chem. Phys. 2003, 118, 1253.

(43) Pal, D.; Chakrabarti, P. J. Mol. Biol. 1999, 294, 271.

(44) Milner-White, E. J. J. Mol. Biol. 1990, 216, 385.

(45) Chin, W.; Dognon, J.-P.; Piuzzi, F.; Tardivel, B.; Dimicoli, I.; Mons, M., in preparation.

(46) Guruprasad, K.; Rajkumar, S. J. Biosci. 2000, 25, 143. 


\section{Supporting Information}

Tables S1 and S2. Most stable B3LYP/6-31+G(d) optimized structures, found for Ac-Phe-Gly-NH 2 and Ac-Gly-Phe- $\mathrm{NH}_{2}$ respectively (assuming trans conformations for all the peptide bonds), sorted according to their type, their number of intramolecular H-bonds and their energy.. Relative B3LYP/6$31+\mathrm{G}(\mathrm{d})$ energies $(\triangle E B 3 L Y P)$, single-point MP2/6-31+G(d)//B3LYP/6-31+G(d) energies $(\triangle E M P 2)$ and scaled B3LYP/6-31+G(d) zero-point vibrational energies $(\triangle Z P E$; scaling factor 0.960$)$ as well as corresponding ZPE-corrected energy values are given in $\mathrm{kcal} / \mathrm{mol}$, with respect to the most stable structure at MP2 level. An average of the ZPE-corrected MP2 energy over the three Phe side-chain orientations is also given for each type of $\beta$-turn. The dihedral angles $\varphi, \psi, \chi_{1}$ describing respectively the relative orientations of the amide bonds about each residue and the Phe side-chain orientation are given in degrees together with the corresponding Ramachandran conformation or the type of $\beta$-turn. 
Table S1

\begin{tabular}{|c|c|c|c|c|c|c|c|c|c|c|c|}
\hline Ac-Phe-Gly-NH ${ }_{2}$ & $\triangle E B 3 L Y P$ & $\triangle E M P 2$ & $\triangle Z P E$ & $\begin{array}{c}\triangle E B 3 L Y P \\
+\triangle Z P E\end{array}$ & $\begin{array}{l}\triangle E M P 2 \\
+\triangle Z P E\end{array}$ & $\begin{array}{r}\chi_{1-} \\
\text { averaged } \\
\triangle E M P 2 \\
+\Delta Z P E\end{array}$ & $\varphi_{\text {Phe }}$ & $\psi_{P h e}$ & $\chi_{1}$ & $\varphi_{G / y}$ & $\psi_{\text {Gly }}$ \\
\hline
\end{tabular}

no H-bond

\begin{tabular}{|c|c|c|c|c|c|c|c|c|c|c|}
\hline$\beta_{\mathrm{L}}(\mathrm{a})-\beta_{\mathrm{L}}$ & 1,19 & 2,72 & $-0,89$ & 0,29 & 1,83 & -155 & 144 & -174 & 177 & -179 \\
\hline \multicolumn{11}{|c|}{ one $\mathrm{H}$-bond } \\
\hline$\beta_{\mathrm{L}}(\mathrm{a})-\gamma_{\mathrm{L}}$ & 0,75 & 0,80 & $-0,30$ & 0,45 & 0,50 & -155 & 163 & -165 & -80 & 62 \\
\hline$\beta_{L}(a)-\gamma_{D}$ & 0,45 & 1,13 & $-0,20$ & 0,26 & 0,93 & -155 & 158 & -169 & 84 & -63 \\
\hline$\gamma_{L}(g+)-\beta_{L}$ & 1,85 & 3,36 & $-0,81$ & 1,05 & 2,56 & -112 & 11 & 56 & 177 & -180 \\
\hline$\gamma_{L}\left(g^{-}\right)-\beta_{L}$ & 3,48 & 5,89 & $-1,12$ & 2,36 & 4,78 & -88 & 82 & -57 & -169 & 173 \\
\hline$\gamma_{L}(a)-\beta_{L}$ & converges & to $\beta(a) \beta$ & & & & & & & & \\
\hline
\end{tabular}

two H-bonds

\begin{tabular}{|lcccccccrrr|}
\hline$\gamma_{\mathrm{L}}(\mathrm{g}-)-\gamma_{D}$ & 0,26 & 0,85 & $-0,06$ & 0,20 & $\mathbf{0 , 7 9}$ & -85 & 70 & -58 & 79 & -61 \\
$\gamma_{\mathrm{L}}(\mathrm{g}+)-\gamma_{\mathrm{L}}$ & 0,34 & 0,92 & 0,24 & 0,58 & $\mathbf{1 , 1 6}$ & -82 & 57 & 43 & -82 & 58 \\
$\gamma_{\mathrm{L}}(\mathrm{g}-)-\gamma_{\mathrm{L}}$ & 0,30 & 1,69 & $-0,07$ & 0,23 & $\mathbf{1 , 6 2}$ & -85 & 67 & -57 & -83 & 60 \\
$\gamma_{\mathrm{D}}(\mathrm{g}-)-\gamma_{\mathrm{D}}$ & 1,41 & 1,71 & $-0,06$ & 1,35 & $\mathbf{1 , 6 5}$ & 73 & -52 & -58 & 82 & -60 \\
$\gamma_{\mathrm{L}}(\mathrm{g}+)-\gamma_{\mathrm{D}}$ & 0,52 & 1,47 & 0,28 & 0,80 & $\mathbf{1 , 7 5}$ & -83 & 61 & 42 & 81 & -64 \\
\hline
\end{tabular}

$\beta$-turns

\begin{tabular}{|c|c|c|c|c|c|c|c|c|c|c|c|}
\hline type I $(\mathrm{g}+)$ & 0,91 & $-0,05$ & 0,06 & 0,97 & 0,01 & & -80 & -2 & 55 & -103 & 8 \\
\hline type I (g-) & 0,77 & 0,87 & $-0,04$ & 0,74 & 0,83 & 1,60 & -71 & -19 & -58 & -99 & 10 \\
\hline type I (a) & 4,57 & 4,30 & $-0,34$ & 4,24 & 3,97 & & -66 & -29 & -172 & -97 & 12 \\
\hline type l' (g+) & 6,11 & 1,28 & $-0,01$ & 6,10 & 1,27 & & 51 & 38 & 53 & 99 & -10 \\
\hline type l' (g-) & 2,21 & 3,47 & $-0,07$ & 2,14 & 3,40 & 3,30 & 64 & 26 & -60 & 100 & -11 \\
\hline type l' (a) & 4,90 & 5,29 & $-0,07$ & 4,83 & 5,22 & & 62 & 34 & -134 & 98 & -12 \\
\hline type II (a) & 0,00 & 0,00 & 0,00 & 0,00 & 0,00 & & -65 & 121 & 174 & 105 & -11 \\
\hline type II (g-) & 0,30 & 1,19 & $-0,10$ & 0,20 & 1,09 & 0,88 & -61 & 125 & -55 & 101 & -12 \\
\hline type II (g+) & 2,06 & 1,50 & 0,04 & 2,10 & 1,54 & & -61 & 134 & 47 & 98 & -14 \\
\hline type II' (g-) & 3,00 & 2,86 & 0,09 & 3,09 & 2,95 & & 55 & -126 & -60 & -101 & 14 \\
\hline type II' (a) & 4,15 & 3,22 & $-0,05$ & 4,10 & 3,17 & 3,99 & 55 & -132 & -170 & -101 & 15 \\
\hline type II' (g+) & 7,72 & 5,72 & 0,11 & 7,84 & 5,84 & & 39 & -120 & 65 & -101 & 15 \\
\hline
\end{tabular}


Table S2

\begin{tabular}{|c|c|c|c|c|c|c|c|c|c|c|c|}
\hline Ac-Gly-Phe-NH ${ }_{2}$ & $\triangle E B 3 L Y P$ & $\triangle E M P 2$ & $\triangle Z P E$ & $\begin{array}{c}\triangle E B 3 L Y P+ \\
\triangle Z P E\end{array}$ & $\begin{array}{l}\triangle E M P 2 \\
+\triangle Z P E\end{array}$ & $\begin{array}{r}\chi_{1}- \\
\text { averaged } \\
\triangle E M P 2 \\
+\triangle Z P E\end{array}$ & $\varphi_{G l y}$ & $\psi_{\text {Gly }}$ & $\varphi_{\text {Phe }}$ & $\psi_{\text {Phe }}$ & $\chi_{1}$ \\
\hline
\end{tabular}

\section{no $\mathrm{H}$-bond}

\begin{tabular}{|c|c|c|c|c|c|c|c|c|c|c|}
\hline$\beta_{L}-\beta_{L}(a)$ & -4.23 & 4.44 & -0.63 & $-4,86$ & 3.82 & -180 & -180 & -156 & 161 & -167 \\
\hline
\end{tabular}

\section{one $\mathrm{H}$-bond}

\begin{tabular}{|c|c|c|c|c|c|c|c|c|c|c|}
\hline$\gamma_{D}-\beta_{L}(a)$ & -2.14 & 3.94 & -0.46 & $-2,60$ & 3.48 & 87 & -54 & -150 & 155 & -168 \\
\hline$\gamma_{L}-\beta_{L}(a)$ & -2.03 & 4.00 & -0.39 & $-2,41$ & 3.62 & -86 & 79 & -155 & 153 & -169 \\
\hline$\beta_{L}-\gamma_{L}(g+)$ & -3.25 & 4.91 & -0.26 & $-3,51$ & 4.65 & -180 & -177 & -83 & 53 & 44 \\
\hline$\beta_{L}-\gamma_{L}(g-)$ & -3.14 & 5.59 & -0.55 & $-3,70$ & 5.03 & 176 & -174 & -85 & 73 & -57 \\
\hline$\beta_{L}-\gamma_{L}(a)$ & -2.92 & 6.07 & -0.47 & $-3,40$ & 5.60 & -180 & 179 & -84 & 83 & -165 \\
\hline
\end{tabular}

\section{two H-bonds}

\begin{tabular}{|c|c|c|c|c|c|c|c|c|c|c|}
\hline$\gamma_{L}-\gamma_{L}(g-)$ & -4.22 & 0.61 & 0.04 & $-4,18$ & 0.65 & -82 & 62 & -84 & 71 & -64 \\
\hline$\gamma_{D}-\gamma_{D}(g-)$ & -3.13 & 0.89 & 0.29 & $-2,84$ & 1.18 & 81 & -62 & 74 & -49 & -58 \\
\hline$\gamma_{D}-\gamma_{L}(g-)$ & -4.23 & 1.81 & -0.04 & $-4,27$ & 1.77 & 82 & -66 & -82 & 73 & -63 \\
\hline$\gamma_{L}-\gamma_{L}(g+)$ & -2.32 & 3.18 & -0.97 & $-3,29$ & 2.21 & -85 & 102 & -82 & 49 & 48 \\
\hline$\gamma_{D}-\gamma_{L}(a)$ & -4.06 & 2.44 & 0.07 & $-3,99$ & 2.50 & 82 & -68 & -81 & 82 & -164 \\
\hline$\gamma_{D}-\gamma_{L}(g+)$ & -2.16 & 2.73 & 0.12 & -2.04 & 2.85 & 83 & -77 & -82 & 53 & 46 \\
\hline$\gamma_{L}-\gamma_{D}(g-)$ & -2.84 & 2.88 & 0.23 & $-2,61$ & 3.11 & -82 & 67 & 72 & -52 & -59 \\
\hline$\gamma_{L}-\gamma_{L}(a)$ & -3.83 & 2.99 & 0.15 & $-3,68$ & 3.14 & -82 & 64 & -84 & 79 & -163 \\
\hline
\end{tabular}

\section{$\beta$-turns}

\begin{tabular}{|c|c|c|c|c|c|c|c|c|c|c|c|}
\hline type I (g+) & 0.00 & 0.00 & 0.00 & 0,00 & 0.00 & & -74 & -10 & -101 & 9 & 55 \\
\hline type I (g-) & -2.40 & 2.92 & -0.19 & $-2,59$ & 2.73 & 2.91 & -74 & -10 & -95 & -1 & -61 \\
\hline type I (a) & 0.32 & 6.42 & -0.40 & $-0,08$ & 6.01 & & -75 & -12 & -126 & 39 & -150 \\
\hline type l' (g-) & -0.46 & 3.92 & -0.12 & $-0,58$ & 3.80 & & 71 & 17 & 70 & 17 & -60 \\
\hline type I' (g+) & converges & to $\gamma_{D} \delta_{L}$ & & & - & 5.73 & & & & & \\
\hline type l' a & 2.04 & 7.80 & -0.13 & 1,91 & 7.67 & & 72 & 15 & 66 & 25 & -128 \\
\hline type II (g+) & 0.66 & 3.53 & -0.01 & 0,65 & 3.52 & & -78 & 66 & -173 & -19 & 58 \\
\hline type II (g-) & -1.26 & 3.52 & 0.11 & $-1,15$ & 3.63 & 4.79 & -60 & 135 & 74 & 10 & -60 \\
\hline type II (a) & 1.23 & 7.17 & 0.05 & 1,28 & 7.22 & & -62 & 132 & 68 & 21 & -124 \\
\hline type II' (g+) & -4.49 & 0.28 & 0.20 & $-4,29$ & 0.49 & & 62 & -130 & -100 & 11 & 55 \\
\hline type II' (g-) & -3.41 & 2.40 & -0.04 & $-3,45$ & 2.36 & 2.74 & 62 & -129 & -96 & 5 & -63 \\
\hline type II' (a) & -0.96 & 5.49 & -0.10 & $-1,06$ & 5.39 & & 60 & -129 & -121 & 41 & -151 \\
\hline
\end{tabular}


Tables S3 and S4. Comparison of the experimental near IR frequencies $\left(\mathrm{cm}^{-1}\right)$ with the calculated harmonic frequencies $\left(\mathrm{cm}^{-1}\right.$; scaling factor 0.96$)$, IR intensities $\left(\mathrm{km} \cdot \mathrm{mole}^{-1}\right.$; brackets $)$ and assignment of the four NH stretch modes of the most stable B3LYP/6-31+G(d) optimized structures found for AcPhe-Gly- $\mathrm{NH}_{2}$ and Ac-Gly-Phe- $\mathrm{NH}_{2}$ respectively. The most stable best fit conformations is indicated in bold.

Table S3

\begin{tabular}{|c|c|c|c|c|c|c|c|c|c|}
\hline \multicolumn{2}{|c|}{ Ac-Phe-Gly-NH 2} & \multicolumn{2}{|c|}{ NHPhe } & \multicolumn{2}{|c|}{ NHGly } & \multicolumn{2}{|c|}{$\mathbf{N H}_{2}$ sym. } & \multicolumn{2}{|l|}{$\mathrm{NH}_{2}$ antisym. } \\
\hline \multirow{3}{*}{$\begin{array}{c}\text { Experiment } \\
\text { one H-bor }\end{array}$} & Conf. A & 3444 & & 3449 & & 3381 & & 3523 & \\
\hline & $\beta_{\mathrm{L}}(\mathbf{a})-\gamma_{\mathrm{L}}$ & $3432(77)$ & $C_{5}$ & $3457(66)$ & $\pi$ & $3378(87)$ & $\mathrm{C}_{7}$ & $3527(85)$ & free \\
\hline & $\beta_{L}(a)-\gamma_{D}$ & $3446(71)$ & $\mathrm{C}_{5}$ & $3468(48)$ & $\pi$ & 3379 (102) & $\mathrm{C}_{7}$ & $3529(96)$ & free \\
\hline \multirow{5}{*}{$\begin{array}{c}\text { Experiment } \\
\beta \text {-turns }\end{array}$} & Conf. B & not obs. & & not obs. & & 3387 & & 3522 & \\
\hline & type II (a) & 3465 (27) & free & $3469(25)$ & free & 3374 (261) & $\mathrm{C}_{10}$ & $3520(116)$ & free \\
\hline & type I (g+) & $3443(81)$ & $\pi$ & $3480(30)$ & free & 3390 (178) & $\mathrm{C}_{10}$ & 3526 (117) & free \\
\hline & type I (g-) & $3434(57)$ & $\pi$ & 3468 (29) & free & 3385 (232) & $\mathrm{C}_{10}$ & 3524 (125) & free \\
\hline & type II (g-) & $3474(55)$ & free & $3464(21)$ & free & 3367 (349) & $\mathrm{C}_{10}$ & 3517 (127) & free \\
\hline
\end{tabular}

Table S4

\begin{tabular}{|c|c|c|c|c|c|c|c|c|}
\hline Ac-Gly-Phe-NH 2 & \multicolumn{2}{|c|}{ NHPhe } & \multicolumn{2}{|c|}{ NHGly } & \multicolumn{2}{|c|}{$\mathbf{N H}_{2}$ sym. } & \multicolumn{2}{|l|}{$\mathbf{N H}_{2}$ antisym. } \\
\hline Experiment Conf. A & not obs. & & 3359 & & 3319 & & 3520 & \\
\hline$\gamma_{L}-\gamma_{L}(\mathbf{g}-)$ & $3484(29)$ & free & $3342(157)$ & $\mathrm{C}_{7}$ & $3358(102)$ & $\mathrm{C}_{7}$ & $3516(77)$ & free \\
\hline$\gamma_{D}-\gamma_{D}(g-)$ & $3484(26)$ & free & $3331(237)$ & $\mathrm{C}_{7}$ & $3342(127)$ & $\mathrm{C}_{7}$ & $3517(94)$ & free \\
\hline$\gamma_{D}-\gamma_{L}(\mathbf{g}-)$ & $3485(32)$ & free & $3343(156)$ & $\mathrm{C}_{7}$ & $3355(99)$ & $\mathrm{C}_{7}$ & $3514(67)$ & free \\
\hline \multirow{3}{*}{$\begin{array}{c}\text { Experiment } \\
\beta \text {-turns }\end{array}$} & not obs. & & 3442 & & 3388 & & 3519 & \\
\hline & $3480(26)$ & free & $3455(37)$ & $\pi$ & 3391 (184) & $\mathrm{C}_{10}$ & $3525(104)$ & free \\
\hline & $3487(38)$ & free & $3453(41)$ & $\pi$ & $3380(268)$ & $\mathrm{C}_{10}$ & $3519(106)$ & free \\
\hline
\end{tabular}

